\title{
Frustration leads to radical behaviour
}

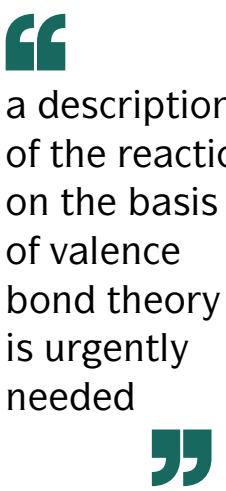

Coordination chemistry rests on dative bonding between a Lewis base and a Lewis acid. This bonding is arrested if there is sufficient steric crowding around the donor and acceptor atoms, as is the case for bulky tertiary phosphines $\mathrm{PR}_{3}$ and boranes $\mathrm{BR}_{3}$ - archetypical frustrated Lewis pairs (FLPs). These are interesting in that they have unquenched nucleophilic and electrophilic atoms, whose respective HOMO and LUMO can work together to activate small molecules such as hydrostannanes $\mathrm{HSnR}_{3}$ to give $\left[\mathrm{R}_{3} \mathrm{SnPR}_{3}\right]^{+}\left[\mathrm{HBR}_{3}\right]^{-}$. Although one can prevent a Lewis base and acid from forming an adduct, the relative energies of frontier orbitals may enable competitive single electron transfer (SET) and formation of a frustrated radical pair (FRP), such as the phosphoniumyl/ boratyl $\left[\mathrm{PR}_{3}\right]^{\cdot}\left[\mathrm{BR}_{3}\right]^{-\cdot}$. Like FLPs, FRPs can split bonds, but do so

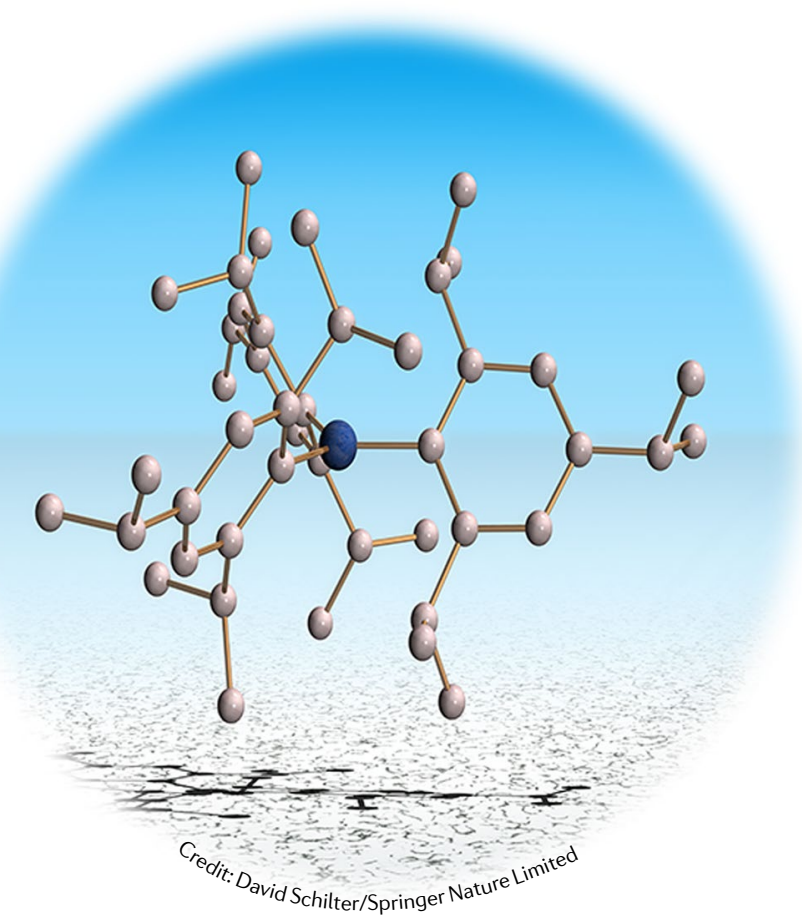

through a homolytic instead of a heterolytic mechanism to afford distinct phosphonium/borate salts $\left[\mathrm{HPR}_{3}\right]^{+}\left[\mathrm{HBR}_{3}\right]^{-}$. This unique chemistry motivated a team led by Thomas Müller and Hendrik Klare to use silylium ions $\left[\mathrm{SiR}_{3}\right]^{+}$to oxidize phosphines $\mathrm{PR}_{3}$ and deliberately generate the more stable $\left[\mathrm{PR}_{3}\right]^{+} \%$ $\left[\mathrm{SiR}_{3}\right]^{\prime}$ FRPs, which they now describe in Angewandte Chemie.

That FLPs cleave hydrostannanes by heterolysis is intuitive, but it would be risky to assume a priori that a similar mechanism is at play for the non-polar substrate $\mathrm{H}_{2}$. "There are theoretical studies that suggest that $\mathrm{PR}_{3} / \mathrm{BR}_{3}$ pairs convert into $\left[\mathrm{HPR}_{3}\right]^{+}\left[\mathrm{HBR}_{3}\right]^{-}$by cleaving $\mathrm{H}_{2}$ in a homolytic fashion, although experimental evidence in support of this mechanism is lacking," notes Müller. Were the reaction to proceed by this radical mechanism, it might be a good idea to begin with a radical pair in the first place. Thus, the team kept the phosphines but replaced the boranes with silylium ions $\left[\mathrm{SiR}_{3}\right]^{+}$, which are strong Lewis acids and oxidants when used with weakly coordinating anions and solvents $\left(\left[\mathrm{B}\left(\mathrm{C}_{6} \mathrm{~F}_{5}\right)_{4}\right]^{-}\right.$and 1,2- $\mathrm{Cl}_{2} \mathrm{C}_{6} \mathrm{H}_{4}$, respectively). The purple colour of certain Lewis base and acid combinations indicated the formation of radicals. At equilibrium, $27 \%$ of $\left[\mathrm{Si}\left(\mathrm{C}_{6} \mathrm{Me}_{5}\right)_{3}\right]^{+} / \mathrm{P}(2,4$, 6- $\left.{ }^{i} \mathrm{Pr}_{3} \mathrm{C}_{6} \mathrm{H}_{2}\right)_{3}$ exists as a $\left[\mathrm{Si}\left(\mathrm{C}_{6} \mathrm{Me}_{5}\right)_{3}\right]^{\circ} /$ $\left[\mathrm{P}\left(2,4,6-{ }^{-} \mathrm{Pr}_{3} \mathrm{C}_{6} \mathrm{H}_{2}\right)_{3}\right]^{+}$. FRP instead of a bona fide FLP. In contrast to the trigonal pyramidal phosphine, the phosphoniumyl radical (shown in the image) has a planar structure reminiscent of the oxidant $\left[\mathrm{N}\left(4-\mathrm{BrC}_{6} \mathrm{H}_{4}\right)_{3}\right]^{+\cdot}$ and triarylamines. It turns out that SET is not limited to FLPs, and the normal Lewis adduct $\left[\left(\mathrm{Si}^{i} \mathrm{Pr}_{3}\right) \mathrm{P}\left(2,4,6-\mathrm{Me}_{3} \mathrm{C}_{6} \mathrm{H}_{2}\right)_{3}\right]^{+}$also exists in part as $\left[\mathrm{Si}^{i} \mathrm{Pr}_{3}\right]^{*} /[\mathrm{P}(2,4$, $\left.\left.6-\mathrm{Me}_{3} \mathrm{C}_{6} \mathrm{H}_{2}\right)_{3}\right]^{+}$. Each phosphoniumyl radical was identified according to electron spin resonance signals featuring ${ }^{31} \mathrm{P}$ hyperfine coupling, but Müller admits that co-formation of putative (and reactive) silyl radicals $\left[\mathrm{SiR}_{3}\right]^{*}$ is yet to be confirmed.

What may seem curious is that silylium cations $\left[\mathrm{SiR}_{3}\right]^{+}$oxidize triarylphosphines $\mathrm{P}\left(2,4,6-{ }^{i} \operatorname{Pr}_{3} \mathrm{C}_{6} \mathrm{H}_{2}\right)_{3}$ and $\mathrm{P}\left(2,4,6-\mathrm{Me}_{3} \mathrm{C}_{6} \mathrm{H}_{2}\right)_{3}$ but not trialkylphosphine $\mathrm{P}^{t} \mathrm{Bu}_{3}$. While it is true that ${ }^{t} \mathrm{Bu}$ is more inductively electron-donating than the aryls, the latter groups are larger, such that the triarylphosphines part with an electron more easily because this would be accompanied by a release of steric strain associated with moving to a planar geometry. Ionization potentials calculated using density-functional theory support these data, but the team wants more thermochemical information about SET. However, the reactivity of the $\left[\mathrm{SiR}_{3}\right]^{\prime}$ products is again problematic in that it hampers electrochemical measurements, let alone any intended substrate conversions.

Experimental challenges aside, the findings of Müller, Klare and colleagues add to our understanding of the interplay between classical Lewis adducts, FLPs and FRPs. What will elevate these species beyond laboratory curiosities is efficient and well-defined reactivity with small molecules, of which $\mathrm{H}_{2}$ is the most topical. "In particular, a description of the reaction on the basis of valence bond theory is urgently needed. This may allow us to distinguish between homolytic and heterolytic pathways in $\mathrm{H}_{2}$ activation," asserts Müller.

David Schilter

ORIGINAL ARTICLE Merk, A. et al.

Single-electron transfer reactions in silylium ion/phosphane frustrated and conventional Lewis pairs. Angew. Chem. Int. Ed. https://doi.org/ 10.1002/anie.201808922 (2018) 